\title{
Metaphor and imaginative consciousness. Translating the contents of higher consciousness into abstract mental pictures
}

\author{
Joseph Bailey \\ Freie Waldorfschule Greifswald, Germany
}

It takes a mind in which poetic spirit and philosophical spirit have completely and utterly interpenetrated.

Novalis

Johannes Kiersch has initiated a noteworthy project devoted to renewing approaches to understanding texts by Rudolf Steiner, with the name "Reading Steiner Differently". He outlines his perspective of the project in his essay entitled Painted from a palette entirely different ${ }^{t}$. In this article, Kiersch points to present-day ill repute of Waldorf education in the academy as the direct result of a false reception of Anthroposophy by Steiner's earliest pupils, and to a means of improving this unfortunate position by changing the way Steiner's works on education are read. According to Kiersch, the disadvantageous position of Waldorf Education is roughly this: the Waldorf schools seem to function well, yielding as they do intelligent, original, well-adjusted, creative, successful members of all levels of society; however, the Waldorf movement's theoretical foundation is academically not acceptable. The reason Kiersch cites for this is that the generations of those who represented Waldorf Education before the positivist academic establishment in the decades immediately following Steiner's passing themselves did so in a positivist manner. So doing, they construed and championed his spoken and written statements literally and dogmatically, thereby placing chief and absolute value on a handful of facts cited as mere examples for the purpose of illustrating processes Steiner expected to be at the teacher's command. Since examples were taken as ends in themselves and the processuality was left by the wayside, by the 1980s, the Waldorf movement no longer had any say in the serious public discourse on education. The "occult" or "esoteric" bent of the "facts" held up and bandied about as Waldorf education's theoretical foundation led to its reputed lack of a scientific approach.

In the course of his article, Kiersch draws attention to the research of a number of authors who more recently have made steps toward developing heuristics (whether they have Anthroposophy or Waldorf Education explicitly in mind or not) suitable for scientific treatment of Anthroposophical content, and he invites the reader each time to follow up on and further this research. Specifically, he refers to work done by the following scholars: ${ }^{2}$

- Hanegraaff, who has outlined an approach toward dealing with esoteric subject matter in general in a way acceptable to "hard science", but without compromising the esoteric content;

- Rittelmeyer, who proposes a methodologic/heuristic approach toward dealing with the theoretical foundations of Waldorf Education;

- Pörksen, whose work pertaining to Goethe's language use in scientific contexts can also provide a key to understanding Steiner.

- Even a contemporary of Steiner's, Ernst Cassirer (and along with him Susanne Langer [1965]), offers a potential heuristic tool in his "discursive symbolism".

It is yet another thread Kiersch points out that I will take up in the present essay. He suggests that careful attention given to psychological fundamentals of the Anthroposophical path of knowledge might contribute to a heuristic rather than empirical understanding of works basic to Waldorf Education. In this context, he mentions the first chapter of The Case for

1. Transl. Norman Skillen. The original German title of this essay is Mit ganz anderen Mitteln gemalt; both versions in 2010, vol. 1 number 2 of the RoSE Journal.

2. For citations of the following authors, please refer to the article by Kiersch (2010). 
Anthroposophy, ${ }^{3}$ published in 1917, which is the original source of the words that make up the title of Kiersch's essay, and bears the title "Anthroposophy and Anthropology". This first chapter is dedicated to establishing between the two eponymous parties a discourse, which he considers both necessary and possible: necessary for the sake of guaranteeing a bona fide natural science; possible due to the inherent compatibility between Steiner's spiritual science - the "Anthroposophy" referred to in its title - and "empiric research of the conventional sort" - the title's "anthropology". Steiner warns, however, that this possibility can only become reality the sharp distinctions existing between the two are not blurred.

But, says Kiersch, just this blurring occurred, "through the special mental climate surrounding the initial reception of Steiner's works" (2010, p. 66). And it is to this "tendency ... to misinterpret the anthroposophical courses for teachers as containing 'anthropological' knowledge" (p. 69) that Kiersch traces the tragic way in which "Waldorf education's adopted 'picture of man' found itself sidelined" (p. 70) - thus not deemed a credible partner for any sort of discourse.

As a contribution to the endeavor to "read Steiner differently", the present essay intends to devote closer attention to psychological fundamentals of the Anthroposopical path of knowledge delineated in the first chapter of The Case for Anthroposophy referred to above. As mentioned, this chapter is the original context of the turn of the word Kiersch uses to title his essay. It is in connection with these psychological fundamentals that "painting with completely different means" becomes an issue at all - if one with a number of interweaving ramifications, among them such broad topics as the discourse to which Steiner's essay is devoted, or the reconciliation within the individual soul between waking consciousness and (potential) supersensible consciousness, without which reconciliation no discourse is possible in the first place; and such - seemingly - narrower ones as processes of consciousness and communication at work within the soul of the author Steiner himself, or the function of the very expression of painting a picture of the human being "from a palette entirely different" as a poetic device. An examination of just this last aspect will enable us to draw conclusions relevant to the crucial role played by the language Steiner uses to communicate those broader topics. And so my own essay attempts an examination of Steiner's essay not only in order to shed light on the original content and context which, when one reads between the lines, can be found to include Steiner's own consciousness - of what he means by "painting" using "completely different means", but also as an occasion to look into the language he uses to do so. ${ }^{4}$

To understand the "completely other means" Anthroposophy uses of "painting" its image of the human being, it may be useful first to take a critical look at the context in which this metaphor occurs. The essay's purpose, as its brief final paragraph reminds the reader, has been to answer the question raised at its beginning concerning "whether fruitful dialogue is possible between anthropology and Anthroposophy" (Steiner, 1970, par. 25). This recapitulation is immediately preceded by the passage that refers to "painting an image of the human being using completely different means." Thus said metaphor occurs at the very end of the essay's main body and in direct connection with the stated purpose of the entire chapter. As a metaphor, the passage communicates an image, or a picture. And if there is any stock in the proverb that a picture is worth a thousand words, it might be a sound assumption that this metaphor's "thousand words" make up a good - if not the main - portion of the essay. Which in turn is dedicated to affirming the possibility of a discourse between spiritual science and the science produced by normal everyday consciousness.

Let us begin by examining the metaphor. The metaphor of providing "an image of man [painted using] methods quite other than those of the image furnished by the humanist philosophy stemming from anthropology" is somewhat complex. In order to show how it is an exact encapsulation of the text - the 'thousand words' leading up to it - I will quote it in its entirety:

Certainly the philosophy of humanity which stems from Anthroposophy will furnish an image of man [painted using] methods quite other than those of the image furnished by the humanist philosophy stemming from anthropology. Yet close observers of the one image and of the other will find that their ideas accord, as the negative plate of a competent photographer accords with his positive print. (Steiner, 1970, par. 24)

These two sentences contain not only the metaphor of the "image of man painted using different methods", but a simile as well, in which the accord of the two images is compared with the accord between the "negative plate" and its "positive print." This simile is actually a condensed recapitulation of the entirety of the paragraph it concludes. A quote of the text the above two sentences recapitulate can serve as a starting point to show how this is so.

Rightly pursued,... the two approaches, anthroposophical and anthropological, converge and meet in one point. Anthroposophy contributes the image of the living human spirit, showing how, through sense existence, this develops the consciousness that obtains between birth and death, while at the same time its supersensible consciousness is deadened. Anthropology contributes [to this encounter] ${ }^{5}$ the image of sensuous man, apprehending in the moment of consciousness his selfhood but towering into a subsistence in the spirit [and living in

3. The original German title of this work is Von Seelenrätseln (literally: On Riddles of the Soul). Today this book is only partly available - in a superb English translation by Owen Barfield - under the title The Case for Anthroposophy.

4. The reader is asked to bear in mind that the generally available Barfield translation of the work does not preserve the literal sense of the original German term I translate as "painting with different means".

5. The words in square brackets convey a more complete impression of Steiner's original elocution in German, which reads as follows: "Anthropologie zeigt bei dem Begegnen das Bild... des Sinnesmenschen..." (Steiner 1960 p. 32). The words in italics („,bei dem Begegnen“) correspond to those in square brackets (,[to this encounter] ${ }^{\prime)}$ in the quote of the English translation. 
that essence which $]^{6}$ extends beyond birth and death. In this coincidence a genuinely fruitful understanding between Anthroposophy and anthropology is possible. It cannot fail, if both disciplines terminate in philosophy and humanity. (Steiner, 1970, par. 23)

\section{The simile}

The points of the accord referred to in the simile of the negative plate and the positive print are the following:

- For Anthroposophy, the two "converge and meet in one point", for anthropology it is - according to Steiner's original German, at any rate - an "encounter", thus something mutual for the former and something adversative for the latter;

- Anthroposophy brings "the image of the living human spirit", while anthropology shows "the image of the sensuous man" in process of "apprehending his... selfhood";

- while the anthroposophically "painted" human being "develops the consciousness that exists between birth and death" and does so "through sense existence", by which "supersensible consciousness is deadened", in the anthropological depiction "sensuous man" lives in the essence "that extends beyond birth and death," since he "towers into a subsistence in the spirit", "apprehending... his selfhood" as he does (my italics, J. B.).

A schematic depiction of these inversions looks like this:

\section{Anthroposophy}

- convergence and meeting in one point

- $\quad$ image of the living spirit man

- $\quad$ [goes] through sense existence

- develops the consciousness that exists between birth and death

- $\quad$ supersensible consciousness is deadened
Anthropology

- encounter [according to Steiner's original German; includes notion of opposition]

- image of sensuous man

- $\quad$ towers into subsistence in the spirit

- lives [in that essence which] extends beyond birth and death

- $\quad$ sensuous man apprehends his selfhood

Thus for each aspect of the one image there is an exact inverse aspect of the other. But that's not all. The points of accord shown above are in turn a condensation of an earlier (par. 14 and 15) at-length and detailed point-for-point juxtaposition of the anthroposophical and the anthropological paths to comprehending the human being, while these paragraphs for their part are an extensive gathering together, a bundling in nearly the form of a chart, of all that Steiner has developed up to then in the first eighteen pages of the chapter. Thus the latter passage actually enacts the precise "accord" the simile refers to between the negative and positive photographic images, while the passage following it - the one immediately preceding the simile - re-enacts the accord in a denser, recapitulative formulation. And the simile itself encapsulates the content and structure of the preceding passage in so highly condensed and exact a way that it can be considered a meditative formula.

\section{The metaphor}

Let's return to the metaphor of "painting a picture of the human being" and first try to understand it in terms of conventional metaphor, that is, as poetic images formed using 'normal' means. Metaphor at large is a special kind of signification, or of designation. In the course of 'normal', non-poetic signification, a word is used to designate a certain set of perceptive qualities that converge to form an object. Thus for example the word "apple" is used to designate a set of sense qualities including "round", "red", sweet", "juicy", etc. In normal designation theory the term "apple" is the designator, the set of corresponding sense qualities the designated. What distinguishes metaphoric designation from this 'normal' signification is that each of its terms, both the designator and the designated, themselves already are a significatory pair consisting of designator and designated. ${ }^{7}$ In metaphoric

6. These words in square brackets are also intended to convey a more complete impression of Steiner's original elocution in German, which reads as follows: "Anthropologie zeigt bei dem Begegnen das Bild des im Bewusstsein sich selbst erfassenden Sinnesmenschen, der aber aufragend in das geistige Dasein in dem Wesen lebt, das über Geburt und Tod hinaus liegt” (Steiner, 1960, p. 32). The words in italics („, in dem Wesen lebt, das") correspond to those in square brackets (, [and living in that essence which]“) in the quote of the English translation.

7. Novalis works out an approach to a theory of designation consisting not of two, but of three terms: sign, designated and designator, whereby the sign assumes the role of conventional sign theory's designator and Novalis' designator refers to the human agency that brings sign and designated into significatory relationship with each other. Cf. volume 2, page 108 of Novalis, Schriften (1977-88). Ed. Richard Samuel et. al. 3rd edition. 5 vols. Stuttgart: Kohlhammer 
designation, the designator is called the vehicle, while the designated is called the tenor.

To give an example, when Shelley refers to colored autumn leaves as "pestilence stricken multitudes", the one significatory pair, "pestilence stricken multitudes", is used to designate - to give new meaning to - the coloration and quantity of a different pair, the colored leaves in autumn. Each pair has meaning in its own right and no causal or genetic connection to the other. Their connection is an associative or analogical one that aligns the leaves' colors and great quantity with the teint of a mass of diseased persons.

Another example: Wordsworth designates "The soul that rises with us" as "our life's star". "The soul that rises with us", the vehicle of this metaphor, designates the human individuality that comes unto its own in the biographical process starting with birth. In the conventional conception of things, this soul or individuality has just as little causal or genetic connection with the tenor, a heavenly body (much less with one belonging to "our life"), as between the significatory pairs in the example quoted from Shelley. But the analogical association lies in the rising both of the "soul" (with birth) and the "star" on the horizon, and this connection, helped along by the coupling of the star with "our life," invites the reader to lend star-like attributes to the soul.

And what are the terms of Steiner's "painting" metaphor? Harmless as it may seem at first glance, it proves under closer examination to be complicated indeed. Even without using the one significatory pair - "painting" plus "a picture of the human being" - as the vehicle of a metaphor, this pair conveys a dual meaning. First, "picture of the human being" (German Bild des Menschen) can connote a portrait, a painting, something one sees with one's physical eyes. Secondly, a "picture" of the human being refers to a "conception" or "notion" or "idea" of the human being. In the given context, of course, it is obvious that the second meaning is intended and that to construe "picture" in the physical sense would be absurd. All the same, there is an associative affinity between "painting" and "picture" in the literal sense, which on a feeling level compensates what for the intellect is absurd: in the given context it is indeed absurd to take "picture" in the concrete, physical sense; but just as absurd - no matter what the context - is the notion of physically painting an inner conception. This intersection between associative and intellectual logic evokes a sense of hovering, gliding or oscillation between the concrete physical and the metaphorical connotation.

When Steiner writes of "a picture of the human being" provided from the anthroposophical side for the discourse between Anthroposophy and anthropology, he clearly intends it with the more inner connotation, thus as a notion or conception of the human being, and not as a painting of the human being; and so the "picture of the human being", taken for itself, is no metaphor. Only when the notion of "painting" this picture enters in does metaphor occur. The reason it is possible to employ the word "painting" in this context without it seeming illogical or absurd is that it is used in the vicinity of the word "picture"; after all, when one paints, one paints a picture. But in this context, the picture as a concrete physical object is not the one referred to by the words Bild des Menschen; rather, it is in the strict sense only assumed. If one were to take the words literally, one would have to understand them to mean the creation of an inner conception or notion by applying material paints to a material surface, which is absurd. As one of the terms of the metaphor, then, "painting" is the explicit part of the vehicle, while its product, the painting, is the vehicle's understood or assumed component. And "picture of the human being" as a notion or conception is the explicit part of the tenor. Now just as the concrete physical picture hovers in the background as the assumed logical completion of the action of "painting", the purely inward activity to which the act of painting as tenor of the metaphor refers likewise remains hovering in the background, is understood as the logical completion of the contextual meaning of "picture of the human being". Its 'concrete', 'literal' sense is that of 'rendering contents of perception as apprehended in imaginative consciousness in a way that is accessible to normal waking consciousness.

Having explored the complexities and subtleties of the metaphor, we can ask now: What does it do in Steiner's text? We have seen how the image presented in the simile of the photographic print and the photographer's negative plate, as a summary of the text passages leading up to it, proves to function as a condensation, an encapsulation of the "accord in all points" or, better, of the "convergence in a single point" of the pictures of the human being provided by anthropology and Anthroposophy, respectively. The metaphor, though, does not recapitulate; rather, it enacts. The dual meaning inherent in the expression "picture of the human being" is a convergence of something concrete and physical ("picture" as an actual painting) with something limited to the contents of consciousness ("picture" as 'conception' or 'notion'). The "picture" as a physical art object corresponds to sense perception, to normal waking consciousness: to anthropology, while with regard to the "picture" as the imagined content of inner consciousness, this consciousness can correspond either to anthropology or Anthroposophy. Thus the two pictures actually converge in the metaphor itself. The metaphor is not merely about the convergence; rather, it enacts this very convergence.

\section{The anthropologist in us all: Sense-awareness's blindness to supersensible consciousness, or: the barrier where sense-knowledge ends}

We have analyzed the expression "painting a picture of the human being" in terms of conventional metaphor. We can go on to explore the means by which the anthroposophical image of the human being is painted in a way that it can make a genuine contribution to the discourse between Anthroposophy and "anthropology". What are the "other means" referred to in the 
metaphor? One way to find an answer to this question is to look into Steiner's striving to make clear what sense-free imaginations are. To this end, he first explains the way sense-bound images come about.

But even before launching into this explanation, he puts a disclaimer on his designation of sense-free perceptions as "imaginative", saying that this term must not be conflated with the unavoidable figurative form of expression used to point in the direction of perceptions of this kind:

In my anthroposophical writings I have applied the term "imaginal" to representations that are apprehended by the psyche as living. It is a misunderstanding to confound the reference of this word with the form of expression (imagery) which has to be employed in order to analogously suggest such representations. (Steiner, 1970, par. 19)

To do so would be to take literally what is meant as an analogical, figurative comparison, as a metaphor of sorts. ${ }^{8}$ As will become evident, it is significant that it is only after this disclaimer Steiner that goes into the production of 'literal' sense-bound notion of the inner images.

He becomes quite explicit about how such images are "painted" to create the contents of normal waking consciousness:

If someone has a sense-perception while the outer object is impressing him, then the perception has a certain inner potency for him. If he turns away from the object, then he can re-present it to himself in a purely internal representation. But the intrinsic strength of the representation has now been reduced. Compared with the representation effected in the presence of the object, it is more or less shadowy. If he wants to enliven these shadowy representations of ordinary consciousness, he impregnates them with echoes of actual [sense] contemplation. He converts the representation into a visual image. Now such images are no other than the joint effects of representation and sensory life combined. (Steiner, 1970, par. 19)

This explanation of how sense images come about is at the same time one of "painting a picture of the human being" from the anthropological perspective. In this case, "painting" - formation of a vivid mental picture of a sense perception - denotes saturation of a "shadowy" mental picture with "echoes of actual contemplation." In terms of the metaphor of painting an image of the human being, these "echoes" are the figurative "paint" in the process that creates the anthropologist's image of the human being.

\section{Gaining sense-free awareness: Keeping images clean of sense content}

Steiner then goes on to stress that this is not the way sense-free images are brought to consciousness; that to bring these about "the act of [imagining] is impregnated from quite another side than in the case of sense-perception":

In order to bring ["imaginal” representations of Anthroposophy] to pass, the soul must be familiar with the inner process that combines psychic representation with sense-impression, so familiar that it can hold at arm's length the influx of the sense-impressions themselves (or of their echoes in after-experience) into the act of representing. This keeping at bay of post-sense-experiences can only be achieved, if the man has detected the way in which the activity of representing is pre-empted by these after experiences. Not until then is he in a position to combine his spiritual organs with the act itself and thereby to receive impressions of spiritual reality.

Thus the act of [imagining] is impregnated from quite another side than in the case of sense-perception. And thus the mental experiences are positively different from those evoked by sense-perception. (Steiner, 1970, par. 20)

The actual perception of sense-free "imaginations" can only be brought about by a separation of sense content, including the "echoes" of sense perception, from the agency "by means of which the soul lives, but of which it can know nothing" (Steiner, 1970, par. 18). Thus while on a purely nominal level Steiner in his disclaimer calls on the reader not to confuse the literal with the imaginative, on a real, practical level - for the sake of actual perception - he calls on the meditant actively to separate sensecontent from sense-free activity.

This act of separation, however, is not yet the "painting with different means"; rather, it is a 'mere' prerequisite for the perception of sense-free imaginations. And this perception is in turn prerequisite to rendering the content of sense-free imaginations in a way understandable for normal waking consciousness. How, specifically, is this done?

\section{The side-effects of perception: the possibility of discourse}

Appendix 4, a footnote of sorts to paragraph 20 of "Anthroposophy and Anthropology", speaks of "adapting" or "transferring" - the German word Steiner uses is "übertragen" - the contents of spiritual perception to normal consciousness, which yields an

8. Steiner's disclaimer is an articulation from the anthroposophical perspective of what in the context of Goethe's natural scientific language Pörksen refers to as Goethean "Sprachskepsis". While according to Pörksen Goethe despairs over the inability of language to capture what is meant, Steiner shifts this burden of understanding onto the reader, expecting him not only to make the effort to gain sense-free perception, but also to distinguish between it and the means of making it understandable to normal waking consciousness. 
"abstract concept" this consciousness can remember, but which is no longer the original supersensible content: "The content of spiritual perception is adapted from beholding consciousness to normal consciousness. Then it becomes an abstract mental picture. And this can be remembered in the normal way." The German language also uses the expression "übertragen" - literally: "carry over", convey (as in conveyer belt) - to refer to metaphor, to symbolic or metaphoric activity, in which a word, an expression that refers to one thing "is applied to something else in such way that here as well it also has valid meaning" (rendered from the 1989 edition of the Duden dictionary, Deutsches Universal Wörterbuch). That is, one conveys one word or expression - transports it, carries it over, adapts it to fit - to a different word or expression, which in turn yields analogical or figurative meaning. (The reader will recall that the word or expression that is 'carried over' or used to designate another word or term is called the vehicle, while the 'other' word or term, the one designated by the vehicle, is called the tenor.)]

Steiner becomes more concrete about adapting the contents of sense-free perception, when in the same paragraph he speaks of a kind of common ground that exists between sense-bound and imaginative perception.

\section{The ethic/aesthetic moment: Metaphor and conveying sense-free meaning}

This common ground is of a feeling and ethical nature within the human soul. It consists in a kind of soul-resonance that, on the one hand, always accompanies sense perception. Steiner delineates how the perception a person has of a particular thing via the physical senses will always be accompanied by a stronger or fainter feeling-resonance specific to this sense impression. He calls this feeling a "side-effect". It inheres not in the percept, but rather in the soul of the perceiver, in which it is merely called forth by this percept. This 'calling forth' can also be characterized as a kind of natural resonating within the soul, which is objective, inasmuch as it is always the same for this particular perception, whether sensed repeatedly by the same person, or by multiple persons. On the other hand, though, the life of feeling likewise resonates in response to sense-free perception, and with the same objectivity as for sense-bound perception. What's more: there are sense-free imaginative perceptions that evoke a collateral feeling resonance that is identical to the feeling resonance evoked by sense-bound representations - despite the radical discreteness of the two kinds of perception. Steiner brings a concrete example for this, using the color yellow. He explains how a certain sense-free perception can evoke an accompanying feeling resonance that is identical to the one called forth by yellow, a sense-bound perception, and how it is possible to make a particular imaginative perception understandable for sense-bound awareness by saying that beholding it is "as if one were seeing the color yellow" [my italics, J. B.]. This is the common ground, the phenomenon that enables communication of the contents of imaginal sensing to a consciousness that does not go beyond what the physiological senses can give it. It is what allows a person to translate his own clairvoyant experiences into normal waking consciousness. It is "painting with different means".

In terms of conventional poetic device, this way of adapting sense-free perception to the contents of sense-bound perception is simile: a rhetorical device, a comparison using "as," "as if," or "like." Surprisingly simple, perhaps; but there are important intrinsic differences between conventional and imaginative figures of speech.

For although a "common ground" and a discreteness between the terms of metaphor also play a role in conveying meaning within sense-bound consciousness, they are of a different nature than in the above adapting of the content of beholding consciousness to normal consciousness. The common ground: both terms of conventional metaphor are sense-accessible. The discreteness: the absence of a causal link between them. According to Shakespeare's 116 Sonnet, for instance, love "is the star to ev'ry wandring bark" ${ }^{10}$ In this metaphor, love guides human beings in a manner comparable to the way the stars guide a ship. The stars' guidance of a ship is the vehicle, designating the tenor love and the (not stated but understood) human being. And when in Sonnet 18 Shakespeare calls the sun "the eye of heaven", ${ }^{11}$ the eye is the vehicle used to convey the image of the sun (which is the tenor) raying out into and taking hold of space, comparable to the act of seeing. To give a further example: when Wordsworth's daffodils appear as a "crowd, a host... dancing in the breeze", even the poet's own heart dances with them. ${ }^{12}$ Wordsworth uses the activity of dancing as the vehicle to designate the character of the daffodils' movement in the breeze and the aesthetic pleasure he takes in it. In all these examples of conventional metaphor, both the vehicle and the tenor are manifest to the senses in one way or another. To cite examples of more difficult, modern metaphor: The ones of Celan's protagonists "drink black milk of the dawn," while others "had earth within them and they dug." Paradoxical and problematic as these metaphors may seem, even they can be analyzed in terms of a vehicle and a tenor, both in some way accessible to the physical senses.

By all commonality of their ontological status as sense perceptible in everyday life, the intellect cannot readily link the terms of these metaphors logically. The poet's challenge consists in establishing this association by means of analogy, comparison, metaphor and other rhetorical stylistic methods. This is a 'logic of images', able to establish an associative, feeling connection between objects that to

9. Barfield renders this passage as follows: "Thereafter, it is true, the duality is modified for practical purposes, through the circumstance that the content of the spiritual perception can be carried over from the intuitive into ordinary-level consciousness."

10. Sonnet 116

11. Sonnet 18

12. Wordsworth, "Daffodils", 1804 
normal waking consciousness are discrete, because they stand in no causal or generic connection to one another. While love, stars and boats; daffodils and the heart and dancing; death, the color black, milk and sunrise; earth, digging and inner soul work all manifest in some way to normal waking consciousness, neither flowers nor the heart dance in the literal sense, nor does love have anything literally to do with the stars; and while a literalistic relation is readily apparent between the sun and the eyes (blinding glare), this is a causal and not an analogical or metaphorical association. The analogical or non-causal association can occur at different aesthetic or moral levels. It can range from base to exalted, from trivial, to profound, but it always involves the element of feeling. ${ }^{13}$

Thus the task the "painter" of an anthroposophical "picture of the human being" faces is a different one than that of the creator of conventional metaphor. As stated above, the challenge posed by beholding consciousness is to convey the meaning of something that for the senses does not exist. ${ }^{14}$ Expressed as terms of metaphor, the sense impression to which the felt-yet-objective side-effect corresponds - in Steiner's example, the color yellow - is the vehicle, and the content of beholding consciousness the tenor. Thus the one term of the comparison does not exist for the senses. The seer seeking to adapt his perception to senseawareness has nothing sense-perceptible that is analogous to the eye Shakespeare uses to designate the sun, or to the dancing Wordsworth uses to characterize the daffodil and the heart. Or even Celan's drinking black milk or digging earth inside oneself. What the terms of metaphor or simile have in common in designation involving imaginative consciousness is not the level of existence, but rather the feeling side-effect.

The above examples from Shakespeare, Wordsworth and Celan demonstrate the causal discreteness between the terms of conventional metaphor. They juxtapose two sets of sense-perceptible content having no causal connection (for which reason they are not associated one with the other by a literalist mindset), in order to establish an analogical similarity, which causes the soul to resonate at a level of feeling or emotion. Thus a feeling resonance is the end result of conventional metaphor, is its goal or objective. The place of feeling resonance in conveying the contents of sense-free perception in sense-bound terms is a different one. The sense-related content designates the sense-free content based on an already existing objective feeling-ethical resonance evoked in the soul by both. Thus the feeling or ethical element is not the goal of metaphoric activity, but rather its prerequisite.

The major analogies Steiner uses in "Anthroposophy and Anthropology" concerning the grains of wheat and the blind person who develops his sense of touch are 'imaginative' similes involving the lack of a sense-perceptible tenor.

\section{The anthropologist within}

In each case where Steiner uses such similes to communicate the contents of sense-free experience to sense-bound consciousness, one can assume that an equally simple but absolutely indispensable task of distinguishing between the phases involved in adapting supersensible content to fit sense-bound consciousness has been strictly adhered to.

We have seen that these phases, delineated in the essay "Anthroposophy and Anthropology" and appendix 4 of The Case for Anthroposophy, call for

1. keeping images free of sense-content; this involves the elimination of all physiological influences necessary for memory; and

2. making the contents of beholding (supersensible) consciousness accessible to normal consciousness by rendering these contents as "abstract mental pictures" suited for normal ("anthropological") consciousness.

But of equally crucial importance is learning to distinguish between

1. the above soul processes that lead to spiritual perception;

2. the spiritual perceptions themselves;

3. the abstract mental pictures into which these perceptions are adapted. ${ }^{15}$

13. Among the most lasting, noblest of metaphors, whose topicality spans millennia, are those whose feeling element is a sensing of the truth. Truth as a matter not of causality, not of the intellect, not of emotions, but of the heart.

14. This challenge is not new. The Apocalypse, for instance, describes God the Father in this way: “... behold, a throne was set in heaven, and One sat on the throne. And he that sat was to look upon like a jasper and a sardius stone..." (Book of Revelations, 4:2,3). Benesch comments on this mode of vision:

$[\mathrm{O}]$ ne begins to divine this entity not as appearing supersensibly in fatherly human shape, but rather as One sitting on a throne (a being One, a throning One), and this entity being "the same as" - "to look upon like" - the stone jasper and sard... Thus the Father God is not jasper, sard and emerald; rather. He manifests supersensibly, imaginatively in the way that jasper, sard and emerald appear sensibly. From this it can be concluded that the sense perceptible manifestation of these precious stones bears something within them that is at least inwardly related, if not identical to, the spiritual appearance of the Godhead as primal entity (translated from Benesch, Apokalypse. Die Verwandlung der Erde. Eine okkulte Mineralogie, pp. 69 f.).

The "inward relatedness" Benesch refers to would be what St. John sensed as the ethical resonance within his soul common to the (supersensible) divine Creator and the (sense-perceptible) precious stones.

15. Cf. appendices 1 and 4 of The Case for Anthroposophy. 
Thus, paradoxically, to establish a connection between the two different states of awareness (2.), it is necessary first to disconnect them (1.); and to maintain such a connection it is necessary to distinguish between the processes that enable it (3.). The necessity to distinguish clearly between the phases of this bridging does not cease, though, once the bridging has been accomplished; indeed, it becomes more complicated. For not only must actual supersensible perception (4.) be distinguished from the bodily preconditions that need to hold in order for these perceptions to take place at all; as well, it needs to be distinguished from the abstract mental pictures into which it is rendered for the sake of apprehension by normal waking consciousness (5.). Hence not only do both these levels of consciousness remain radically discrete notwithstanding their living within one and the same soul; but this soul must gain and retain awareness of their discreteness. This is the purpose of the exercise in distinguishing between the phases of attaining and passing on supersensible experience whose mastery on the part of the first generation of Steiner pupils would have preempted their general failure at keeping the two territories of the sense-bound and the supersensible separate.

In other words, one must be careful not to indulge the misconception that in the soul in which both everyday consciousness and higher consciousness live the two states of consciousness somehow simply meld or flow into one another. To do so would be just as false as it is for sense-bound consciousness to believe that since it is not aware of the sense-free being it is based on, this being does not exist in the same soul.

To be sure: it is the nature of sense-bound consciousness not to be aware of higher consciousness. Not even if the two are housed in one and the same soul. But, as “The Case for Anthroposophy" points out, the 'compatibility' referred to above is meant not as the commingling of these two states, but rather as non-interference, as openness, as non-exclusion of the possibility of I-conscious awareness of sense-free states.

Now while in the context of The Case for Anthroposophy the rendering of sense-free imaginations in a way that makes their content accessible to normal waking consciousness ("painting with different means") is performed for the sake of providing a notion of the human being that can be brought into the cultural world at large as a contribution to discourse between Anthroposophy and anthropology, it is clear from the above that it is also something that must be enacted within the individual consciousness of anyone seeking to reconcile their own normal waking consciousness with their own (potential) sense-free imaginative consciousness.

Normal waking consciousness is 'the anthropologist inside everyone'.

\section{The discourse within}

The very necessity to differentiate between the above processes demonstrates a sort of archetype of the discourse between the two utterly distinct states of awareness: the ability to behold free of the senses, and perceiving and knowing restricted to the bounds of the sense barrier.

Pertaining to the discourse Steiner seeks to enter into, in the foreword to The Case for Anthroposophy he states its necessity, which he founds on his conviction that "the cognitive means of true natural scientific observation must demand it as something necessary." It is for this reason that he sees himself compelled to justify the anthroposophical path of knowledge. He even goes so far as to assert that "an anthroposophical spiritual science must exist if the anthropological insights of natural science want to be what they must demand to be" (my italics, J. B.). Thus the discourse is a necessity for the sake of the honesty, authenticity and genuinity of natural science.

In the opening paragraph of "Anthroposophy and Anthropology" Steiner claims the discourse's possibility, since Anthroposophy picks up where anthropology leaves off in the soul processes of cognition. Founding the claim of this possibility is the object of the essay "Anthroposophy and Anthropology."

Now: if we see sense-bound consciousness and processes derived from it as characteristic of the anthropologist, and sense-free consciousness and related processes as characteristic of the seer, and if we bear in mind the radical ontological separation between the two, we can see how performing these processes involved in differentiating and bridging the gap between the two states of consciousness and their contents necessarily involves the enactment within the individual soul of a prototype or archetype of the discourse Steiner sought in the cultural life at large.

\section{The anthroposophist within: Keeping images free of sense-content}

While one has gone so far as to call sense-bound consciousness the 'anthropologist' in every soul, the inverse does not hold: sensefree consciousness is not tantamount to the 'Anthroposophist within'. Anthroposophy only comes about when the impulses of the spiritual world become active in the sense-world - including its influence in the individual soul - by way of the self-conscious human I. 
The Anthroposophy Steiner describes is not simply spiritual consciousness with no connection to normal consciousness. Rather, it is the establishment and maintaining of a connection between "higher" and "normal" consciousness by a mode of knowledge whose constant task it is to distinguish between the different phases of this establishing and maintaining process. The student who fails at making these distinctions will lose either his "higher consciousness" or his soul's health, or both. Steiner's anthroposophist is not the one who merely knows abstract notions referring to the spiritual world; nor is he even the one who merely commands sense-free perception alone; rather, the anthroposophist is the one who straddles various levels of consciousness and is able to distinguish and effect transitions between them. In other words, waking presence to the content both of sense perception and sense-free consciousness is nested within the mode of knowledge of the anthroposophist. And so even the anthroposophist bears 'an anthropologist within' inasmuch as he has a sense-bound consciousness he must strive to come to terms with.

This must have been the case even for Rudolf Steiner himself. Even and especially he will have had to distinguish constantly between the different phases of establishing and maintaining the connection between the "anthropologist within him" and his sense-free consciousness. When considering the "other means," then, that Anthroposophy uses to "paint a picture of the human being," when seeking new approaches to reading Steiner, I suggest we reflect on the processes in motion within himself as a seer, a teacher, perhaps also as a writer.

It does not seem unreasonable to claim that in order to be able to see the need he sensed for discourse in the first place and then to contribute to answering it, he, Rudolf Steiner, first had to bring it about within himself. To the uninitiated, one limitation he does not seem ever to have had was any lack of access to sense-free experience. However, it is likely that, over the well-known ease on his part to attain spiritual experience, people generally oversee what must have been a genuine dilemma to him - notwithstanding explicit reference he made to the loneliness he felt in his childhood and youth. Steiner refers in Christianity as Mystical Fact to a nightmarish, crushing feeling Christ must have endured over the realization that multitudes of souls were lost, in spiritual darkness. And Rudolf Steiner himself doubtless had similar feelings as impulsers of his striving to enter into the discourse he speaks of. But what must have been a problematic specific to his particular historical context and mission is his soul's presence to 'extraordinary' states of consciousness, with which by his own account he was confronted from earliest youth on. Even after his attainment to public renown such states were the source not only of permanent loneliness for him, but also of endless misunderstanding on the part of the general public and even of those closest to him. Such misunderstanding will also have been at the root of the transgression Kiersch refers to against the "territorial separation" Steiner called for.

Moreover, it can be assumed that Steiner remained confronted even within his own soul by the radical unsuitedness of normal waking consciousness to existence beyond the threshold to the spiritual world. It is generally known to scholars of How to Attain Knowledge of Higher Worlds, An Outline of Occult Science, or Theosophy - to name only the most prominent of his works that deal explicitly with the anthroposophical path of knowledge - that normal waking consciousness can be made 'compatible' to the higher states of knowledge through energetic self-education and mutual permeation of the lives of thinking, feeling and willing; it is a foregone conclusion that the seer and teacher himself must have been adept in establishing and maintaining such compatibility.

But we need to draw a crucial distinction between the soul-configuration of Steiner - as the first person in human evolution to publish a theory and practice of productive interaction between the intellect and sense-free knowing - and that of his students and the general public: the point of departure Steiner assumes for the anthroposophical path of development is sense-bound consciousness with no connection to "higher" consciousness, the point of departure for his own development was full consciousness of the supersensible that existed parallel to normal waking consciousness within the soul of a child. This parallel existence does not seem to have disturbed the child himself. Despite clairvoyant experiences of the type in which his relative sprang into the oven and notwithstanding his assessment by the people around him as eccentric whenever he reported such experiences to them, there is no reason to assume the child was not healthy. Perhaps it was a sort of instinct on his part to maintain the wholeness of his personality that spurred him to find means to bridge the gap between the two modes of consciousness. He speaks of childhood experiences he had - such as his discovery of geometry, his experience of the cultic symbolism in the Roman Catholic mass, his clandestine readings of Kant during history class, to cite episodes he mentions in his autobiography - that he found replicated the spiritual reality of which he had unmediated awareness. And it was likely experiences of this kind that kept - or helped keep him on an even keel. Again, though: it would be wrong to assume that the wholeness of his soul life consisted in the two states of consciousness somehow blending or flowing into one another. The feeling side-effect that 'hovers' between two different kinds of perception is autonomous of perception of any kind. It is the soul that hovers between higher and lower levels of consciousness.

To sum up: This essay is intended as one of a number of possible approaches to "reading Steiner differently" proposed by Kiersch in his article Painted from a palette entirely different, the main thrust of which is to promote a heuristic processual understanding of works basic to Waldorf Education, rather than an empirical, dogmatic one. It undertakes to interpret a number of aspects of Steiner's essay Anthropology and Anthroposophy, by way of analysing the key image at this essay's conclusion first as conventional figurative language, then as enactment of the process of imaginative consciousness. The analysis seeks to shed light 
on Steiner's observations that normal sense-bound consciousness and sense-free consciousness are radically discrete. Its results:

- this radical difference normal sense-bound consciousness and sense-free consciousness can only be bridged by an ethical element in the host soul, which element hovers between the two levels of consciousness/existence and thus can establish coherency between them;

- this coherency is archetypal for a discourse Steiner sought to initiate between Anthroposophy and anthropology;

- the need he sensed for this discourse stems from the need he experienced to bridge the gap between two radically different states of consciousness within his own soul.

This essay goes on to observe that the discourse between Anthroposophy and anthropology is inherent in the make-up of the human soul at large and that it will involve each bringing its own different pictures of the human being into dialog, enabling the two to converge and thus come to a mutual understanding. 


\section{References}

Benesch, F. (1981). Apokalypse. Die Verwandlung der Erde. Eine okkulte Mineralogie. Stuttgart: Urachhaus

Kiersch, J. (2010). Mit ganz anderen Mitteln gemalt. RoSE: Research on Steiner Education, 1(2).

Kiersch, J. (2010). Painted from a palette entirely different. RoSE: Research on Steiner Education, 1(2).

Novalis, Schriften (1977-88). Ed. Richard Samuel et. al. 3rd edition. Stuttgart: Kohlhammer

Steiner, R. (1970). The Case for Anthroposophy. Selections from Von Seelenrätseln. Translated, arranged and with an introduction by Owen Barfield. Available at http://wn.rsarchive.org/Books/GA021/English/RSP1970/GA021_index.html [Retrieved 24 Nov., 2011].

Steiner, R. (1960). Von Seelenrätseln. Dornach: Verlag der Rudolf Steiner-Nachlassverwaltung 